\title{
Morpho-criteria and karyotype studies in three mulberry varieties
}

\author{
K. H. Venkatesh \\ Mulberry Breeding and Genetics Laboratory, Department of Sericulture and Life \\ Science, Bangalore University, Bangalore -560056, India \\ Auther Correspondence: (Khvenki1972@gmail.com) \\ Received September 10, 2015; accepted november 12, 2015
}

\begin{abstract}
Morpho-criteria, karyotype analysis, chromosome number and ploidy levels were studied for three mulberry varieties. Mysore local and RFS- ${ }_{175}$ is diploid with $2 \mathrm{n}=28$ and $\mathrm{BC}_{2-59}$ is triploid with $2 \mathrm{n}=42$ somatic chromosomes numbers respectively. Somatic chromosome length ranges from $1.29 \mu \mathrm{m}$ to $3.29 \mu \mathrm{m}$ where as arm ratio ranges from 0.59 to $1.00 \mu \mathrm{m}$. Karyotypes of these taxa are symmetric. Only metacentric and submetacentric chromosomes are found in the somatic complement. Stomatal frequency is lesser in triploid variety when compared to diploid varieties.
\end{abstract}

KEYWORDS: Mulberry (Morus spp.), morphology, diploids, triploid, mitosis, karyotype analysis

The foliage of the mulberry plant is used mainly as a unique source of silkworm (Bombyx mori L.) feed. In addition to feed to silkworms, mulberry is also used in industry, medicine, agro forest and social forest (Bari 1990, Dandin et al. 1992, Kannan and Misri 1990). Most of the cultivated varieties of mulberry are diploids with $2 \mathrm{n}=28$ chromosomes, but a few are polyploids (Gill and Gupta 1979, Venkatesh 2007). Venkatesh and Munirajappa $(2012,2013)$ studied the meiotic behaviors of triploid $(2 n=42)$ and tetraploid $(2 n=56)$ varieties of Morus. Triploids are developed through natural or controlled hybridization between diploid and tetraploid parents and are considered to superior than diploids and tetraploids in leaf yield and nutritive qualities of leaf. Venkatesh et al. (2013) studied the micro morphology and reproductive characteristics of different ploidy level of the mulberry varieties and are considered diploid parents are superior to triploid and tetraploid. Venkatesh et al. (2014) studied the morphological, anatomical and reproductive parameters in different ploidy levels of mulberry varieties. These different chromosomes numbers has reflected on their micromophology, anatomy and reproductive characters of diploid, triploid and tetraploid varieties. Venkatesh et al. (2012) studied the meiotic studies of diploid $(2 \mathrm{n}=28)$ varieties of Morus and confirmed the extreme difference between the 13 small pairs and one large pair of chromosomes. In the present study, is focused on the morphology and karyomorphological details in three varieties of mulberry.

\section{Materials and Methods}

Morphology Mulberry varieties used in the present study are Mysore local, RFS- ${ }_{175}$ and $\mathrm{BC}_{2-59}$ which are maintained in the germplasm bank, Department of Sericulture, Bangalore University, Bangalore, India. Cuttings of these varieties were planted in pots for experimental use. Morphological characters are critically examined at different stages of growth and development.
Following the procedure laid down in the mulberry descriptor (Dandin and Jolly 1986).

Mitosis Somatic preparations were made from excised root tips of potted plants. Root tips were collected between 9.45 to $10.30 \mathrm{a} . \mathrm{m}$. and pre-treated with $0.002 \mathrm{M}$ 8 - hydroxyquinoline for 3 hours at $10^{\circ} \mathrm{c}$. After washing in water the root tips were hydrolyzed in $1 \mathrm{~N} \mathrm{HCl}$ for seven minutes at $50^{\circ} \mathrm{c}$ and then stained with $2 \%$ acetoorcein. Squash preparations were made in $45 \%$ acetic acid. Photomicrographs and drawings were made on the same day of preparation. For each variety numbers of preparations were made to ascertain the chromosome number and their morphology. Ideograms were drawn using suitable scale. Karyotype classicification was made according to Leven et al. (1964).

Stomatal frequency Stomatal frequency was determined by nail polish impression method. Stomatal frequency was calculated by using the formula and expressed as number of stomata/ $\mathrm{mm}^{2}$ (Aneja, 2001; Sikdar et al., 1986).

Stomatal frequency $=\frac{\text { Number of Stomata }}{\text { Area of microscopic field }} \times \mathrm{mm}^{2}$

\section{Results And Discussion}

Variety Mysore local This variety is also called "Natikaddi". It was introduced to Karnataka during the period of Tippu Sultan. It is best suited for rain fed condition. Stem is woody, cylindrical, clothed with many lenticels and green to brown in color. Milky latex present in the stem. Leaves are simple, thin, light green, coriaceous, chordate, lobed serrate, acuminate, exhibited medium height, short, thick petiole and longer internode. Stomatal frequency was found to be 174.24/ $\mathrm{mm}^{2}$ (Fig. 1) and pollen stain ability was $96.32 \%$. It is diploid genotype $2 \mathrm{n}=28$ chromosomes (Fig. 2). Somatic chromosomes are measuring $2.20 \mu \mathrm{m}$ to $3.29 \mu \mathrm{m}$ in length. The karyotype formula of this genotype is $2 \mathrm{n}=$ 
$28=22 \mathrm{~B}^{\mathrm{m}}+6 \mathrm{~B}^{\mathrm{sm}}$ (Fig. 3). The total chromatin length of the haploid set is $38.26 \mu \mathrm{m}$.

Variety $R F S_{175}$ This variety is recommended for cultivation under rain fed condition. Stem is woody, cylindrical, clothed with many lenticels. It is purple green to greenish brown in color, filled with milky latex. Leaves are larger, thin, dark green, coriaceous, chordate, lobed, serrate, and acuminate, it exhibited medium in height, shorter internode, short and slender petiole. Stomatal frequency was found to be 181.81/ $\mathrm{mm}^{2}$ (Figs. 4) and pollen stain ability $96.18 \%$. It is also diploid genotype with $2 \mathrm{n}=28$ chromosomes (Fig. 5). Somatic chromosomes are measuring $1.32 \mu \mathrm{m}$ to $2.26 \mu$ $\mathrm{m}$ in length. The karyotype formula of this genotype is $2 \mathrm{n}=28=2 \mathrm{~B}^{\mathrm{m}}+8 \mathrm{~B}^{\mathrm{sm}}+14 \mathrm{C}^{\mathrm{m}}+4 \mathrm{C}^{\mathrm{sm}}$ (Fig. 6). The total chromatin length of the haploid set is $26.20 \mu \mathrm{m}$.

Variety $B C_{2-59}$ It is a triploid variety. Stem of this taxon is woody, cylindrical, clothed with many lenticels and green in color. Milky latex present in the stem. Leaves are simple, thick, dark green, cortaceous, chordate, unlobed, dentate, acuminate, exhibited maximum height, long, thick petiole and shorter internode. Stomatal frequency was found to be $133.33 / \mathrm{mm}^{2}$ (Fig. 7) and pollen stain ability $91.42 \%$. It is triploid genotype with $2 \mathrm{n}=42$ chromosomes (Fig. 8). Somatic chromosomes are small measuring $1.29 \mu \mathrm{m}$ to $3.19 \mu \mathrm{m}$ in length. Metacentric and sub-metacentric chromosomes are found in the somatic complement. The karyotype formula of this genotype is $2 \mathrm{n}=42=6 \mathrm{~B}^{\mathrm{m}}+26 \mathrm{~B}^{\mathrm{sm}}+$ $6 C^{m}+4 C^{\text {sm }}$ (Fig. 9). The total chromatin length of the haploid set is $47.55 \mu \mathrm{m}$. Morphological comparison and karyomorphological details between the three varieties is given in Tables 1 and 2 .

Tikadar and Dandin (2007) and Venkatesh et al., (2013) studied exomorphic features in some mulberry genotypes and recorded morphological variations. These variations are largely due to genetic flux operating on the evolution of different mulberry variants. Morphological characters are strongly heritable in nature and expected to manifest in the environment. These characters are used in genetic identity and to distinguish between varieties. (Dandin and Kumar; 1989).

Varieties Mysore local, $\mathrm{RFS}_{175}$ and $\mathrm{BC}_{2-59}$ are morphologically distinct and exhibited some similarities in stem and leaves color with identical leaf margin. Dissimilarities in their height, internodal distance, leaf texture and nature, stomatal frequency, size and pollen stain ability. Variety $\mathrm{BC}_{2-59}$ is triploid have similarity in their adaptation $\mathrm{i}$ e. better rooting, grow more quickly and posses larger leaves. Leaves are unlobed, thick, dark green and course in texture when compared to diploid varieties. However, leaves of diploids are lobed, thin, light green and course in texture. The frequency and size of stomata per unit area is significantly less in triploid compared to diploids. Stomatal frequency is an important parameter in selecting drought resistant genotype. Stomatal frequency correlated with drought and disease resistant (Hatalli et al. 1993; Nautiyal et al.,1994). Further lesser frequency and smaller size of stomata per unit area is more suitable for rain fed conditions.

Perusal of the existing literature on chromosome numbers for the genus Morus clearly indicates the occurrence of $2 n=28$ to $2 n=308$. However, Janaki Ammal (1948) has reported chromosome number of $2 n=26$ in $M$. alba. It is a stray report and this number $(2 n=26)$ has not been so far reported by other investigators. Das (1961) and Datta (1954) have reported basic number of $\mathrm{x}=7$ for Morus based on the presence of secondary association in few varieties of $M$. indica. But in the present study as well as the observations made by others rule out the existence of secondary association of chromosomes in majority of Morus spp. (Venkatesh 2007).

In the present investigation on cytological studies in the genus Morus analyzes the chromosome number, ploidy level, karyotype, and Stomatal frequency in three different mulberry genotypes. Among these, the present study recorded the diploid number $(2 n=48)$ in two mulberry genotypes (Mysore local and RFS- ${ }_{175}$ ) and triploid chromosome number $(2 \mathrm{n}=42)$ in one of the mulberry variety $\left(\mathrm{BC}_{2-59}\right)$ studied.

Mulberry varieties included in the present work exhibited variations in ploidy level and karyomorphology. Mysore local and $\mathrm{RFS}_{175}$ have revealed the diploid chromosome of $2 n=28$. Mulberry variety $\mathrm{BC}_{2-59}$ has displayed the triploid chromosome number of $2 n=42$. In general, the chromosomes are short, fairly uniform in their size and form a graded series. Only metacentric and sub metacentric chromosomes are found in the somatic complement of these taxa. The differences in the chromosome size within the respective complement are not very significant. The karyotype is symmetrical. The chromosome length ranges from $1.29 \mu \mathrm{m}$ to $3.29 \mu \mathrm{m}$. Although gross similarities among the karyotypes suggest their homogenous assemblage, yet each cultivar shows certain chromosomal differences from the others retaining their individual pattern (Figs. 7, 8 and 9). Such karyotypic variation in different varieties/ species of the genus Morus L. clearly indicates that the chromosomal repatterning is involved in speciation.

\section{Conclusion}

Morphology and karyomorphological studies of three cultivars namely, Mysore local, $\mathrm{RFS}_{175}$ and $\mathrm{BC}_{2-59}$ belonging to Morus alba. Morphological variations are attributed to genetic drift, it can be resolved that morphological variations and evolution of Morus spp. is mainly due to structural changes in the ployploidization and mutation. Of the three cultivars, two are diploid $(2 n=28)$ and one is triploid $(2 n=42)$. Chromosomes are short, fairly uniform in their size and form a graded series. Only metacentric and sub metacentric chromosomes are found in the somatic complement of these taxa. Morphological variation and evolution of taxa were attributed to structural changes in the karyotype and phylogenetic relationship among the varieties of each species based on their karyotype. 


\section{Literature Cited}

Aneja, K. R. 2001. Experiments in microbiology plant pathology tissue culture and mushroom production technology ( $3^{\text {rd }}$ edition) New age international publishers New Delhi.

Bari, M. A. 1990. The self supporting mulberry Dike-fish pond ecosystem Indian Silk 29 (10): 22-23.

Dandin, S. B. and Jolly. M. S. 1986. Mulberry descriptor. Sericologia 26 (4): 465-475.

Dandin, S. B. and Kumar. 1989. Evaluation of mulberry genotypes for different growth and yield parameters. In: Genetic resources of mulberry and utilization. Edt. by Sengupta, K. and Dandin , S. B., C.S.R.and T.I., Mysore 143-152.

Dandin, S. B., Ranganatha Sastry, K. N. and Bongale, V. D. 1992. Mulberry in wasteland development programme Indian Silk 26 (3): 12-14.

Das, B. C. 1961. Cytological studies on Morus indica L and M laevigata Wall Caryologia 14:159-62.

Datta. M. 1954. Cytological studies in the species of Morus. Cytologia 19: 86-95.

Gill. G. S. and Gupta. R. C. 1979. Cytological studies the sex types of Morus alba, L. (Moraceae). Current Sci. 48 (1): 35-36.

Hatalli. S. R. Chetty. M. B. and Koti. R. V. 1993. Interrelationship of stomatal frequency interveinal distance and yield under depleting soil moisture regime in wheat genotypes Indian Journ. Plant Physiol. 36: 187 188 .

Janaki Ammal. E. K. 1948. The origin of black mulberry. Journ. Roy. Hort. Soc. 75: 117-120.

Kannan. P. and Misri. S. S. 1990. Mulberry cultivation under social forestry scheme in Mysore istrict Indian Silk 29 (5): 23-24.
Levan. A. Fredga, K. and Sandberg, A. A. 1964. Hereditas 52: 201-220.

Nautiyal, S., Badola, H. K., Pal, H. and Negi, D. S. 1994. Plant responses to water stress changes in growth dry matter production Stomatal frequency and leaf anatomy Biol.Plant 36 (1): 91- 97.

Sikdar, A. K., Jolly, M. S., Susheelamma, B. N. and Giridhar, K. 1986. Stomatal chloroplast count technique as a tool to ascertain different ploidy level in mulberry Indian Journ. Seric. 25: 88-90.

Tikadar and Dandin, S. B. 2007. Pre-breeding efforts to utilize two wild Morus species. Current Sci. 92: 1729-1733.

Venkatesh, K. H. 2007. Cytogenetical investigations in the Genus Morus L Ph.D. Dissertation, Bangalore Univ., Bangalore.

Venkatesh, K. H., Munirajappa and Narayanaswamy, V. 2012. Cytological studies in diploid varieties of mulberry. Journ. Cytol. Gen. 13 (NS): 73-77.

Venkatesh. K. H. and Munirajappa. 2012. Cytogenetical studies in two triploid mulberry varieties Journ. Cytol. Gen. 13 (NS): 29-34.

Venkatesh. K. H., Shivaswamy, S. and Munirajappa 2014. Comparative micromorphology and reproductive studies in three mulberry varieties (Moraceae). Int. Journ. Sci. Nat. 4 (4): 608-610.

Venkatesh, K. H., Shivaswamy, S. and Munirajappa 2014. Morphological, anatomical and reproductive parameters in few varieties of mulberry (Morus spp.) Int. Journ. Advanced Biol. Res. 4 (1) 73-75.

Venkatesh. K. H. and Munirajappa 2013. Cytogenetical studies in two tetraploid mulberry varieties (Moraceae). Intern. Soc. Chrom. Bot. 8: 63-67.

Table 1. Comparison of morphological characters in diploids and triploid varieties of mulberries

\begin{tabular}{|l|c|lc|}
\hline \multicolumn{1}{|c|}{ Characters } & Mysore local & RFS $_{175}$ & BC2-59 \\
\hline Height $(\mathrm{cm})$ & 198 & 220 & 231 \\
\hline Number of branches & 07 & 08 & 09 \\
\hline Intermodal distance $(\mathrm{cm})$ & 4.4 & 3.9 & 3.8 \\
\hline Leaf Size $\left(\mathrm{cm}^{2}\right)$ & 149.00 & 161.24 & 172.42 \\
\hline Leaf texture & Light green, thin & Light green, thin & Dark green thick \\
\hline $\begin{array}{l}\text { No. of stomata per unit } \\
\text { area }\left(\mathrm{mm}^{2}\right)\end{array}$ & 174.24 & 181.81 & 133.33 \\
\hline Length of stomata $(\mu \mathrm{m})$ & 12.6 & 13.9 & 13.00 \\
\hline Width of stomata $(\mu \mathrm{m})$ & 10.22 & 11.00 & 10.98 \\
\hline Length of petiole $(\mathrm{cm})$ & 13.9 & 15.8 & 12.60 \\
\hline Width of petiole $(\mathrm{cm})$ & 0.9 & 1.1 & 3.8 \\
\hline Length of inflorescence $(\mathrm{cm})$ & 3.1 & 3.4 & 3.1 \\
\hline Width of inflorescence $(\mathrm{cm})$ & 2.2 & 2.7 & 1.6 \\
\hline $\begin{array}{l}\text { Diameter of inflorescence } \\
(\mathrm{cm})\end{array}$ & 1.1 & 1.3 & 31 \\
\hline $\begin{array}{l}\text { No. of flowers per } \\
\text { inflorescence }\end{array}$ & 22 & 27 & 0.72 \\
\hline Length of flower $(\mathrm{cm})$ & 0.60 & 0.68 & 91.42 \\
\hline Pollen stain ability $(\%)$ & 96.32 & 96.18 & \\
\hline
\end{tabular}




\section{VENKATESH}

Table 2. Karyomorphological details among three mulberry varieties

\begin{tabular}{|c|c|c|c|c|c|c|c|}
\hline $\begin{array}{l}\text { Mulberry } \\
\text { varieties }\end{array}$ & $\begin{array}{l}\text { Stomatal } \\
\text { frequency/ } \\
\mathrm{mm}^{2}\end{array}$ & $\begin{array}{c}2 \mathrm{n} \\
\text { chromosome } \\
\text { number }\end{array}$ & $\begin{array}{l}\text { Ploidy } \\
\text { level }\end{array}$ & Karyotype formulae & $\begin{array}{c}\text { Range of } \\
\text { chromosome } \\
\text { Length }\left(\mu_{\mathrm{m}}\right)\end{array}$ & $\underset{\left(\mu_{\mathrm{m}}\right)}{\operatorname{Arm} \text { ratio }}$ & $\begin{array}{c}\text { Haploid } \\
\text { chromatin } \\
\text { Length }\left(\mu_{\mathrm{m}}\right)\end{array}$ \\
\hline $\begin{array}{l}\text { Mysore } \\
\text { local }\end{array}$ & 174.24 & 28 & Diploid & $2 \mathrm{n}=28=22 \mathrm{~B}^{\mathrm{m}}+6 \mathrm{~B}^{\mathrm{sm}}$ & $2.20-3.29$ & $0.62-1.00$ & 38.26 \\
\hline RFS $_{175}$ & 181.81 & 28 & Diploid & $2 \mathrm{n}=28=2 \mathrm{~B}^{\mathrm{m}}+8 \mathrm{~B}^{\mathrm{sm}}+14 \mathrm{C}^{\mathrm{m}}+4 \mathrm{C}^{\mathrm{sm}}$ & $1.32-2.26$ & $0.73-1.00$ & 26.20 \\
\hline $\mathrm{BC} 2-_{59}$ & 133.33 & 42 & Triploid & $2 \mathrm{n}=42=6 \mathrm{~B}^{\mathrm{m}}+26 \mathrm{~B}^{\mathrm{sm}}+6 \mathrm{C}^{\mathrm{m}}+4 \mathrm{C}^{\mathrm{sm}}$ & $1.29-3.19$ & $0.55-0.92$ & 47.55 \\
\hline
\end{tabular}
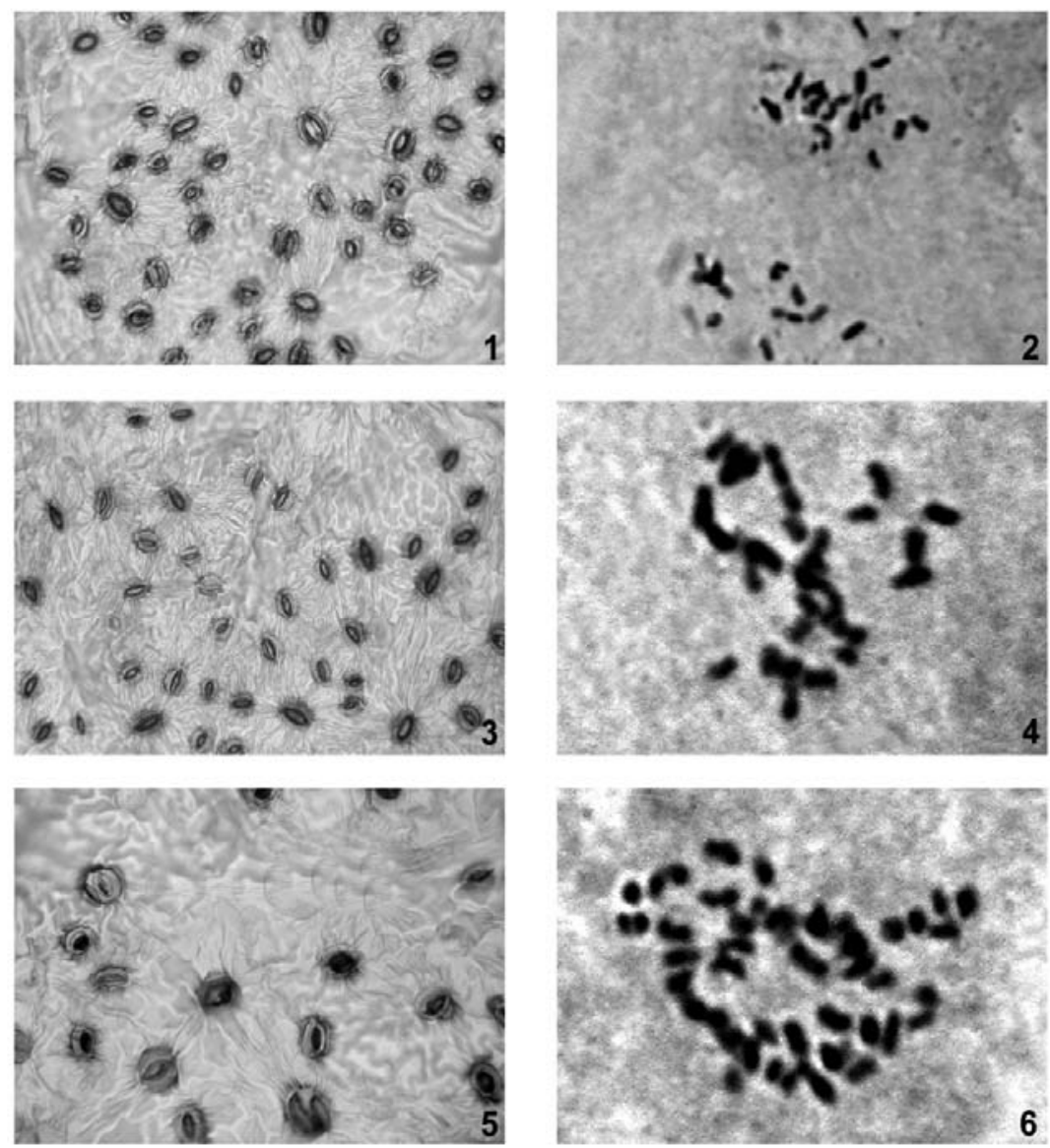

Figs. 1-6. Differences in stomatal frequencies and somatic chromosome numbers among three different varieties of mulberries. 1 and 2. Stomatal frequency and somatic chromosomes $(2 \mathrm{n}=28)$ of variety Mysore local. 3 and 4. Stomatal frequency and somatic chromosomes $(2 \mathrm{n}=28)$ of variety $\mathrm{RFS}_{175} \cdot 5$ and 6 . Stomatal requency and somatic chromosomes $(2 \mathrm{n}=42)$ of variety $\mathrm{BC}_{2-59}$. 

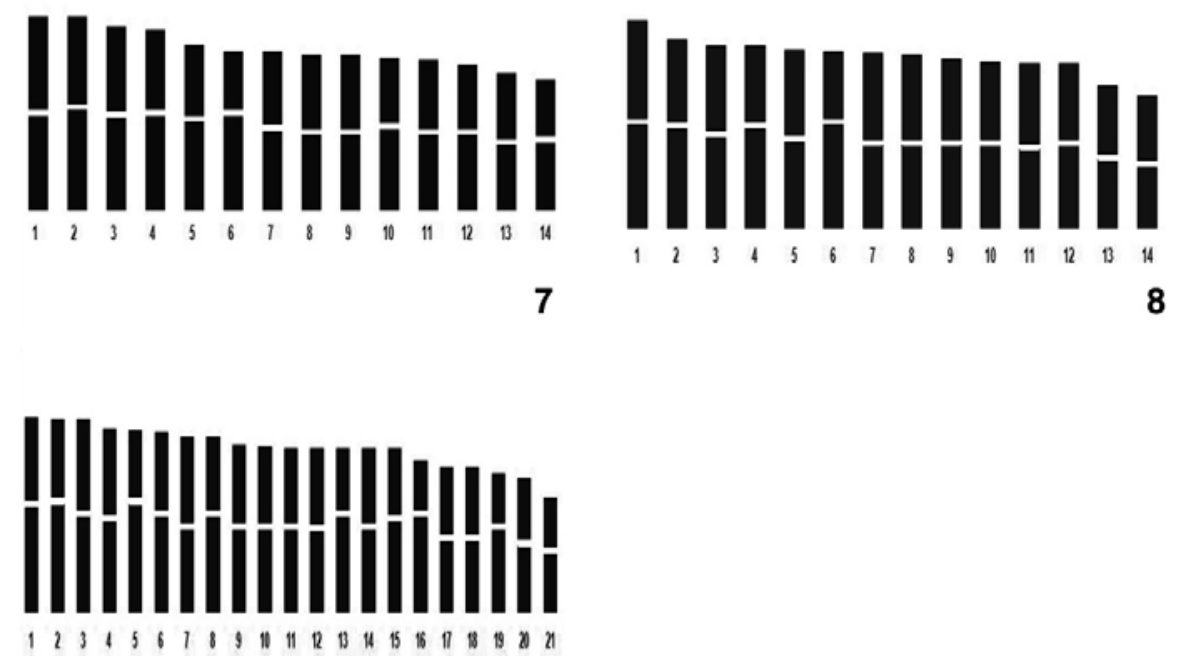

9

Figs. 7-9. Ideograms of karyotypes in different varieties of mulberry 7. Variety Mysore local. 8. RFS175. 9. BC2-59. 